INDO GLOBAL JOURNAL OF

PHARMACEUTICAL SCIENCES

ISSN 2249- 1023

\title{
Biofortification: Combating Micronutrient Deficiencies in India
}

\author{
Meghna Singh, Soumya Soni, Pooja Upadhyay, Priyansh Srivastava, Vibha Gupta * \\ Department of Biotechnology, Jaypee Institute of Information Technology, Noida, U.P.- 201307, India
}

Address for Correspondance: Vibha Gupta, vibha.gupta@jiit.ac.in

\begin{abstract}
Keywords
Biofortification;

Golden Rice;

Orange-fleshed

Sweet Potato;

Dhanshakti.
\end{abstract}

\begin{abstract}
The diets of over two-thirds of the world's population lack one or more essential mineral elements. Staple diet of people in developing countries like India is based on cereals and is not sufficient to provide essential minerals and vitamins like iodine, iron, zinc and vitamin A. Micronutrient deficiency in such countries is one of the major cause of death and disability and a serious health challenge. Biofortification, a promising approach to address micronutrient malnutrition worldwide refers to the development of micronutrient enhanced staple crop varieties by traditional breeding practices or by modern biotechnology. The main focus of this review is to discuss the groundbreaking work on (i) Golden rice, (ii) 2016 malnutrition award winning orange-fleshed sweet potato and (iii) Dhanshakti - the first high iron biofortified pearl millet crop commercialized in India. The review concludes with an assessment of controversies and challenges for biofortification, especially in India.@ 2016 iGlobal Research and Publishing Foundation. All rights reserved.
\end{abstract}

Conference Proceedings: International Conference on Advances in Plant and Microbial Biotechnology (PMB2017); JIIT, Noida: February 02-04, 2017

Indo Global Journal of Pharmaceutical Sciences( ISSN 22491023 ; CODEN- IGJPAI; NLM ID: 101610675) indexed and abstracted in EMBASE(Elsevier), SCIRUS(Elsevier),CABI, CAB Abstracts, Chemical Abstract Services(CAS), American Chemical Society(ACS), Index Copernicus, EBSCO, DOAJ, Google Scholar and many more. For further details, visit http://iglobaljournal.com 